\title{
Familial Hypomagnesemia-A Follow-Up Examination of Three Patients After 9 to 12 Years of Treatment
}

\author{
JOHAN H. STRØMME, ${ }^{(4)}$ JON STEEN-JOHNSEN, KRISTIAN HARNAES, FRIDJAR HOFSTAD, AND \\ PETTER BRANDTZAEG \\ Department of Clinical Chemistry [J. H. S.] and Pediatric Department [P. B.], Ullevål Hospital, Oslo, Norway, and \\ Pediatric Departments of Telemark (J.S-J.), Østfold [K. H.], and Oppland (Gjøvik) [F. H.] County Hospital, Norway
}

\section{Summary}

Three children with familial hypomagnesemia from infancy were treated perorally with magnesium for 9 to 12 years. Their somatic and intellectual development have since been normal. Without therapy, the serum magnesium fell from subnormal (about 0.5 mmoles/liter) to very low values $(0.2$ to $0.3 \mathrm{mmoles} / \mathrm{liter})$ within 1 to $4 \mathrm{wk}$. We observed a secondary fall in serum calcium and potassium and an increase in sodium and phosphate although serum concentrations of PTH, calcitonin, and 25-OH-vitamin D in the blood remained normal. Balance studies confirmed the presence of a defect in the intestinal absorption of magnesium and excluded a defective renal tubular transport system. The subjects continued to require daily magnesium supplements to avoid serious symptoms. Optimal dosage was found to be in the range 0.5 to $0.75 \mathrm{mmoles} / \mathrm{kg} \bullet$ day; doses above this caused diarrhoea and a fall in the serum and urine levels of magnesium. Pathophysiologic mechanisms involved in the electrolyte changes that occurred secondarily to the hypomagnesemia are discussed.

\section{Speculation}

The pathophysiologic basis for the impaired intestinal absorption of magnesium in this condition is unknown. In fact, the mechanism by which magnesium is normally transported across membranes is also largely unknown. A facilitated transport mechanism seems to be involved. It appears reasonable to believe that errors in enzymes, or perhaps more likely, in specific magnesiumbinding proteins that are involved in the membrane transport form the molecular basis for familial hypomagnesemia.

Familial hypomagnesemia was first described in 1965 (23). Subsequently, a total of 18 cases have been reported $(2,4,6,7,10$, $13,15,19,23,24,26,28,30,31,32,34,37)$. In addition, five older siblings of these index cases died with a clinical picture consistent with familial hypomagnesemia, but without a verified diagnosis (Table 1). The usual age of onset was 2 to $4 \mathrm{wk}$; however, two women first became symptomatic during adulthood. This type of congenital primary hypomagnesemia appears to be due to a specific defect in the intestinal absorption of magnesium $(28,32)$.

For 9 to 12 years, we have followed three children with familial hypomagnesemia diagnosed during infancy. In the absence of data from long-term follow-up studies, we have reviewed our subjects as to their growth and development and evaluated their need for extra magnesium supplementation and the degree of homeostatic lability.

\section{SUBJECTS AND METHODS}

\section{SUBJECTS}

M. M., born 6/11/66, was the first child of healthy, nonconsanguineous parents. Symptoms of hypomagnesemia appeared at the age of $4 \mathrm{wk}$. The development during the first 18 months has been reported previously (28). He was treated daily with oral magnesium lactate powder until 12 years of age, followed by a magnesium sulphate mixture $(0.75 \mathrm{mmoles} / \mathrm{kg} \cdot$ day $)$. He has developed normally without convulsions. His serum magnesium has consistently been subnormal: 0.5 to 0.6 mmoles/liter.

T. B., born $8 / 16 / 67$, was the second child of healthy, nonconsanguineous parents. He was born at term after a normal pregnancy and delivery. Symptoms of hypomagnesemia appeared at the age of $3 \mathrm{wk}$. The course through infancy has previously been reported (32). From the fourth wk of life, he received daily supplements of magnesium lactate solution. This was changed at 2 years of age to a magnesium sulphate mixture $(0.75$ mmoles $/ \mathrm{kg}$. day). Despite this medication, his magnesium has been subnormal ( 0.5 to $0.6 \mathrm{mmoles} / \mathrm{liter})$. On two occasions when the supplements were temporarily discontinued, the serum magnesium fell to 0.3 mmoles/liter. His development has been normal, and neither convulsions nor muscular irritability has occurred. Frequently, he has had loose stools.

In 1966, an older sibling died at the age of $7 \mathrm{wk}$ after prolonged hypocalcemic convulsions which were resistant to calcium therapy. A subsequent pregnancy in 1976 ended in a spontaneous abortion at $20 \mathrm{wk}$ of gestation.

K. T. born $2 / 23 / 69$, was the fourth child of nonconsanguineous, healthy parents. Their first child was a boy who died at $8 \mathrm{wk}$. He had failed to thrive and had muscular weakness but no convulsions. Two younger brothers are healthy.

The patient was born 2 wk preterm with a birth weight of 2830 $\mathrm{g}$ and a length of $50 \mathrm{~cm}$. He was breastfed and progressed normally for the first month. He then had several short fits characterized by stiffness and opisthotonus. The symtoms subsided after administration of phenobarbital but reappeared 5 days later. Hypomagnesemia and hypocalcemia were then detected. Treatment was initiated with parenteral and later with oral magnesium. Balance studies at 3 months of age, performed as previously described (32), showed a net intestinal absorption of magnesium of $18 \%$, but a normal absorption of calcium (48\% of intake) and phosphate $(59 \%$ of intake). Seventy-eight percent of a single oral load of ${ }^{85} \mathrm{SrCl}_{2}$ $(2 \mu \mathrm{Ci})$ was absorbed, suggesting a normal absorption of strontium. Magnesium supplementation was initially given as lactate powder and later as a sulphate mixture $(0.50 \mathrm{mmoles} / \mathrm{kg} \cdot$ day $)$. A part from occasional loose stools, he has been asymptomatic but with subnormal serum magnesium levels ( 0.5 to $0.6 \mathrm{mmoles} / \mathrm{liter})$. His development has been normal.

\section{OUTPATIENT STUDIES (38)}

During the first part of the study, the subjects were treated with standardized doses of oral magnesium supplements $(0.75$ mmoles/ $\mathrm{kg}$. day) for $4 \mathrm{wk}$. Then the magnesium therapy was discontinued, and the subjects were reviewed at weekly intervals. If clinical symptoms or signs appeared or the serum magnesium dropped below $0.3 \mathrm{mmole} / \mathrm{liter}$, the therapy was resumed in a stepwise 
fashion. Initially, $0.25 \mathrm{mmole} / \mathrm{kg}$. day was given. When a steady state was reached, usually after 3 to $4 \mathrm{wk}$, another $0.25 \mathrm{mmole} / \mathrm{kg}$. day was added. The oral supplementation was thus increased in increments of $0.25 \mathrm{mmole} / \mathrm{kg}$. day until diarrhoea occurred and/ or the serum magnesium began to fall.

\section{INPATIENT STUDIES (38)}

The subsequent investigation was performed in the hospital. Apart from a clinical and extensive biochemical examination, this comprised a balance study lasting 7 days during which time the dietary intake as well as the fecal and urinary excretion of magnesium, calcium, sodium, potassium, phosphate, and nitrogen were quantitated. Carmine red served as marker of intestinal passage. A peroral load of ${ }^{85}$ strontium chloride (The Radiochemical Center, Ammersham, England) was given to examine the intestinal absorption of this metal. Magnesium supplementation was discontinued 2 wk (M. M. and K. T.) and 5 days (T. B.) wk before the balance studies. Magnesium was administered therapeutically as sulphate, usually perorally as a mixture $(0.5$ mole/

Table 1. Familial hypomagnesemia ${ }^{1}$

\begin{tabular}{lccc}
\hline & \multicolumn{2}{c}{ No. of patients } & \\
\cline { 2 - 3 } \multicolumn{1}{c}{ Sex } & Verified & $\begin{array}{c}\text { Probable at onset } \\
\text { (on history) }\end{array}$ & $\begin{array}{c}\text { Af symptoms } \\
\text { (wk) }\end{array}$ \\
\hline Male & $12(1)^{2}$ & $4(4)$ & $2-30$ \\
Female & $6(0)$ & $1(1)$ & 3-adult ${ }^{3}$ \\
\hline
\end{tabular}

'Number of patients reported in the literature (for references see the text).

${ }^{2}$ Numbers in parentheses, number of deaths.

${ }^{3}$ Two were adults, the other five were below 8 wk of age.
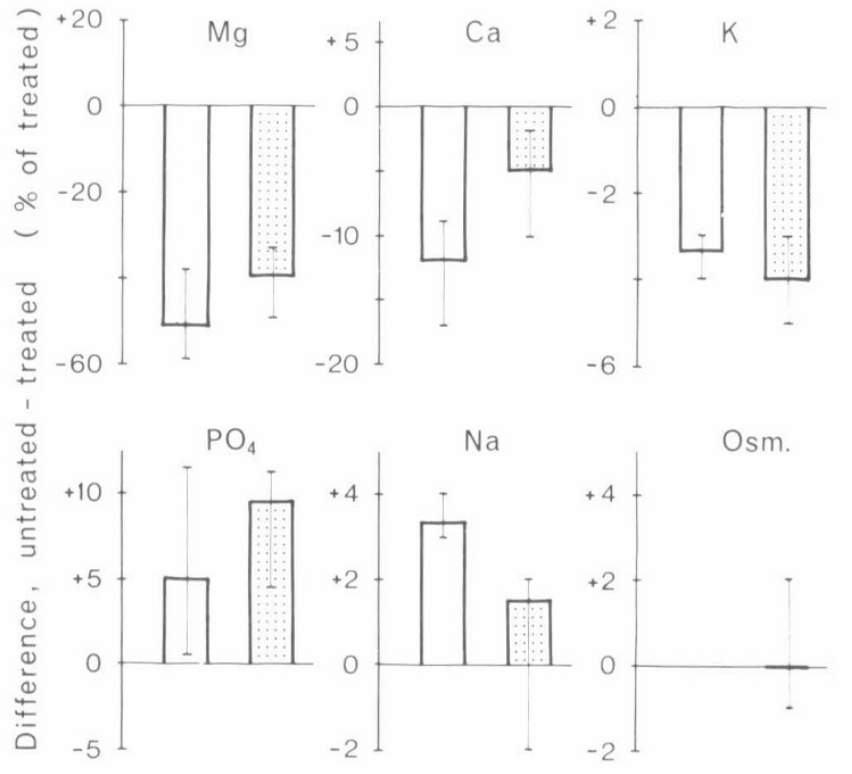

First test period

Second test period

Fig. 1. Difference in levels of serum electrolytes (magnesium, calcium, potassium, phosphate, sodium, and osmolality) during periods without magnesium therapy compared to those found while on therapy. The differences are expressed in percent of the values found during treatment. They are given as mean values of the three patients (columns) and ranges (brackets). Values from both the outpatient examination (open columns) (serum values found immediately before restarting as compared to those before stopping therapy; Figs. 3 to 5) and from the hospital examination (shaded columns) (values after 3 days as compared to those after 7 days in hospital; Fig. 6). liter) and occasionally intramuscularly dissolved in water (1 mole/ liter).

\section{LABORATORY METHODS}

Various hematologic parameters, electrolytes, and small-molecular components, proteins, amino acids, and enzymes were measured by conventional methods. Magnesium, calcium, and zinc were assayed by atomic absorption spectrophotometry. Ionized calcium was determined in serum (anaerobically handled) using an ion-selective electrode (F 2112 Ca; Calcium Selectrode, Radiometer, Denmark). Immunoreactive parathyroid hormone was determined (39) by a C-terminal specific radioimmunoassay as recently described by Gautvik et al. (12). Antisera from rooster which was raised against bovine parathyroid hormone (PTH) and which cross-reacted with human hormone was used as antibody, and ${ }^{125}$ I-labeled purified bovine PTH was used as tracer. The

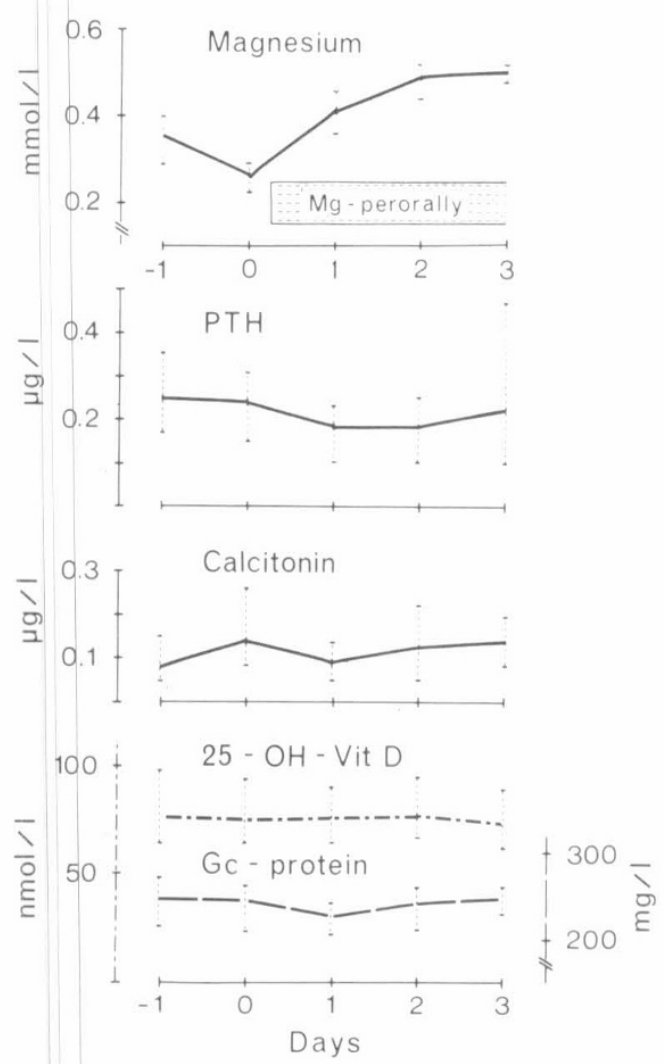

Fig. 2. Serum magnesium, PTH, calcitonin, 25-OH-vitamin D (left ordinate), and Gc-protein (right ordinate) of the three patients before and after the load of magnesium $(0.5 \mathrm{mmole} / \mathrm{kg} \cdot$ day) during the period in hospital. The lines represent the mean values, and the brackets give the ranges.

Table 2. Intestinal absorption (percentage of intake) of electrolytes and nitrogen in the three patients $(M . M ., T . B . \text {, and } K . T .)^{1}$

\begin{tabular}{l|cccc}
\hline \multirow{2}{*}{\multicolumn{1}{c}{ Component }} & M. M. & T. B. & K. T. & Mean \\
\cline { 2 - 4 }$(\%)$
\end{tabular}

${ }^{1}$ Results from balance studies over 7 days. During this period the three children were on a free diet, which was found to give an average daily intake of magnesium from 7.5 to 10.5 mmoles, of calcium from 21 to 25 mmoles, and of phosphate from 31 to 39 mmoles. An oral load of ${ }^{85} \mathrm{SrCl}_{2}$ $(5 / \mu \mathrm{Ci}, 8$ nmoles $)$ was given at the start. 
MM

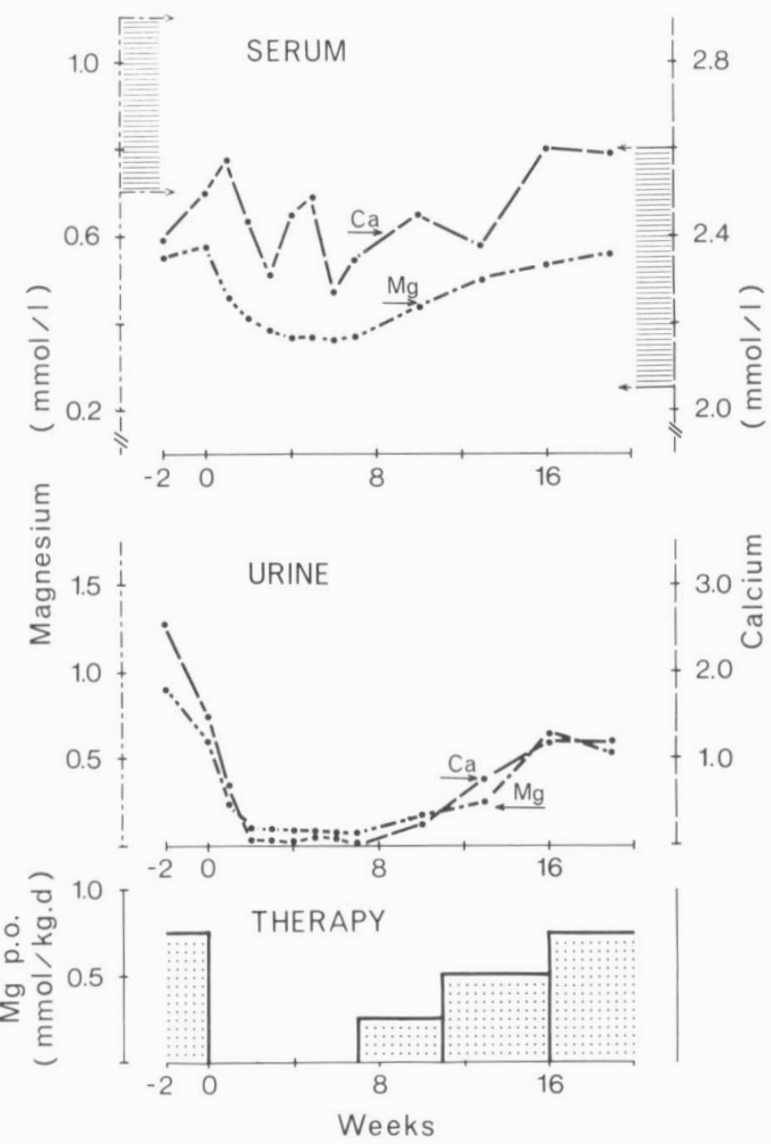

TB

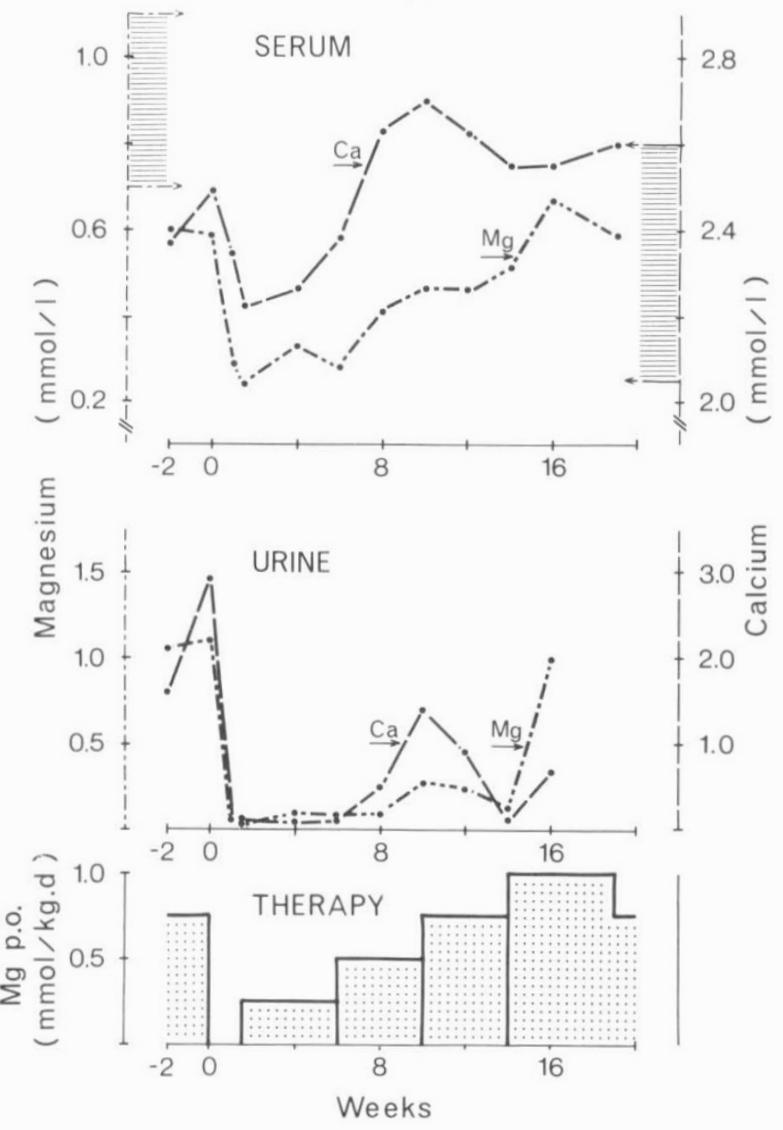

KT
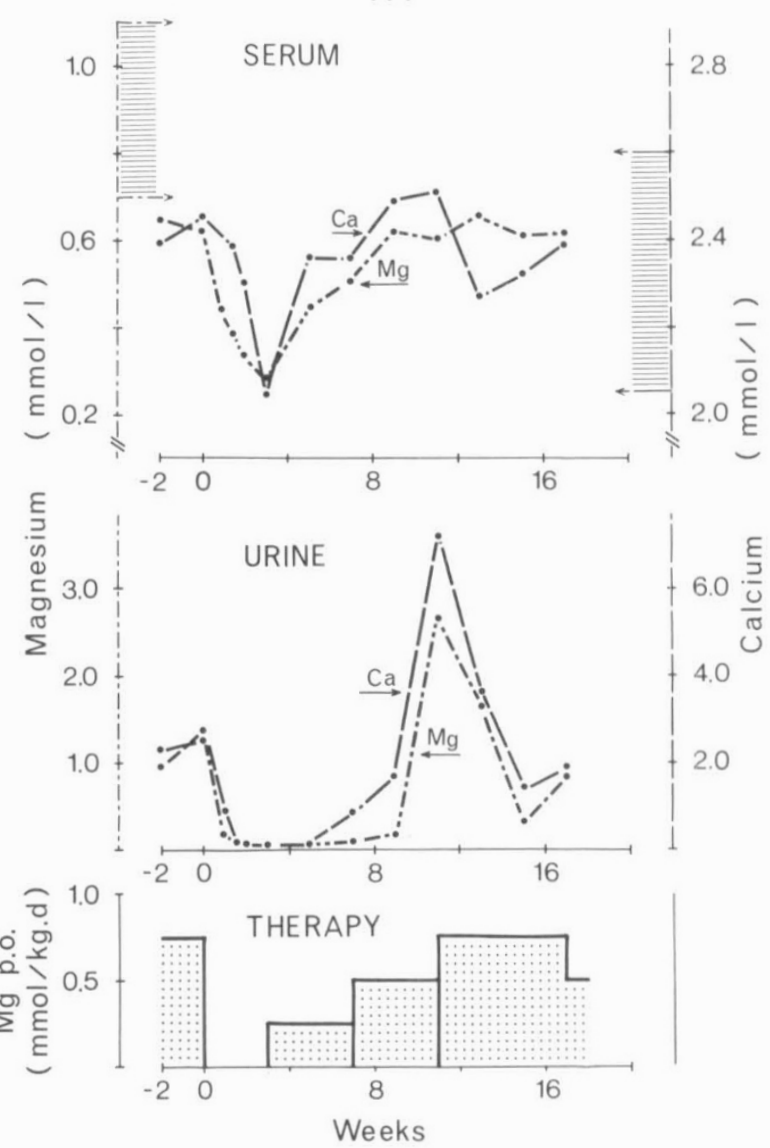

Figs. 3, 4, and 5. Concentration of magnesium (left ordinate) and calcium (right ordinate) in serum (upper part) and urine (middle part) of the three patients (M. M., Fig. 3; T. B., Fig. 4; K. T. Fig. 5) during the outpatient examination. The shaded areas indicate the reference ranges. The amounts of extra magnesium given are indicated in the lower part of the figure.

minimum detectable concentration was $0.10 \mu \mathrm{g} /$ liter. Calcitonin was measured (39) by a radioimmunoassay technique (11) with a lower detectable limit of $0.05 \mu \mathrm{g} /$ liter. 25-OH-vitamin D was measured by a competitive protein binding assay (35).

\section{RESULTS}

\section{DEVELOPMENTAL AND CLINICAL STATUS}

The subjects' respective height and weight percentiles on admission to the hospital were: M. M., both 90th; T. B., both just below 50th; K. T., both 30th. Although formal psychological testings were not carried out, the subjects' intellectual status appeared normal, and they performed normally at school. No abnormalities were detected upon clinical examinations [apart from tetanic symptoms and signs which occurred after a long period without magnesium supplementation (see below)]. Their bone ages were normal.

\section{BIOCHEMICAL STATUS}

During periods of magnesium curtailment, low serum concentrations of magnesium developed (see below). Other electrolyte changes also occurred (Fig. 1) which were probably secondary to the hypomagnesemia. Apart from these changes, a remarkably normal biochemical status was found. Thus, various serum components such as proteins (including agarose gel electrophoresis), enzymes (aspartate and alanine aminotransferase, lactate dehydrogenase, $\gamma$-glutamyltransferase, alkaline, and acid phosphatases), urea, creatinine, triglycerides, cholesterol, HDL-cholesterol, 
amino acids in serum and urine, as well as ordinary hematologic parameters were all within the reference ranges. Serum zinc levels (16 to 19 mmoles/liter) were in the higher normal range. Serum hormones, immunoreactive PTH (upper reference limit, $0.6 \mu \mathrm{g}$ / liter), immunoreactive calcitonin (upper reference limit, $0.5 \mu \mathrm{g}$ / liter) and 25-OH-vitamin D (reference range, 20 to $100 \mathrm{nmoles} /$ liter) including the vitamin D binding transport protein [group specific component (Gc) globulin (14)], fell within reference ranges both while on and off magnesium therapy (Fig. 2).

\section{INTESTINAL ABSORPTION}

The results of the balance studies are summarized in Table 2 . An average of $87 \%$ of the magnesium intake was recovered in the feces, with a variation from 78 to $101 \%$. A low level of calcium absorption was also found, ranging from 31 to minus $4 \%$ and the absorption of strontium averaged $17 \%$, whereas the absorption of sodium, potassium, phosphate, and nitrogen was in the high normal range. The glucose tolerance, the xylose tolerance, the vitamin A absorption test, and the Schilling test were normal in all subjects. The fecal fat excretion was $2.1,2.0$, and $1.6 \mathrm{~g} /$ day for M. M., T. B. and K. T., respectively.

\section{RESPONSE TO CURTAILMENT OF MAGNESIUM SUPPLEMENTATION}

During the outpatient period, all three subjects showed a significant decrease in serum $\mathrm{Mg}$ in the first wk without magnesium supplementation (Figs. 3 to 5). T. B.'s magnesium level dropped below $0.3 \mathrm{mmole} /$ liter within 6 days (Fig. 4), and K. T. reached this level within 3 wk (Fig. 5). M. M. reached a steady level of $0.35 \mathrm{mmole} / \mathrm{liter}$ in $4 \mathrm{wk}$ (Fig. 3). During the first $2 \mathrm{wk}$, the urinary magnesium concentration in all subjects fell below 0.1 mmole/liter. A similar decrease occurred in the concentration of calcium in serum and urine (Figs. 3 to 5), but the calcium changes in serum occurred later and were less marked than those of magnesium. In fact, the serum $\mathrm{Ca}$ did not fall below the lower reference limit in any of the subjects during the whole period.

Similar serum (Fig. 6) and urinary changes (not shown) were found during the inpatient period. On admission (off therapy), ionized calcium was between 1.15 and 1.19 mmoles/liter, whereas at discharge (on therapy), it was between 1.23 and 1.25 mmoles/ liter (reference range, 1.10 to $1.30 \mathrm{mmoles} / \mathrm{liter}$ ). The concentration of erythrocyte magnesium (reference range, 1.70 to 3.00 mmoles/liter) was between 1.43 and 1.45 mmoles/liter immediately before therapy and between 1.53 and 1.64 mmoles/liter at discharge. On the fourth day after admission, K. T. demonstrated slight tetanic cramps. The other two subjects had positive Chvostec signs. Oral magnesium supplementation was therefore resumed (0.5 mmole $/ \mathrm{kg}$-day) with $\mathrm{K}$. T. receiving IM magnesium sulphate ( 3 mmoles) immediately. The signs of tetany disappeared within minutes after the injection.

\section{DISCUSSION}

The results of this study show that children with familial hypomagnesemia grow and develop normally when they are given daily oral magnesium supplementation. It was also established that the subjects have a continual need for additional magnesium. Without therapy, the onset of symptoms of hypomagnesemia might be delayed for several wk, provided that there were already replete body stores of the mineral or that the dietary intake of magnesium was high. Optimal oral supplementation of magnesium sulphate was found to be from 0.5 to $0.75 \mathrm{mmole} / \mathrm{kg} \cdot$ day. Higher doses caused diarrhoea, and no further increase in serum $\mathrm{Mg}$ occurred. The subsequent fall in serum and urinary magnesium, which was seen on high doses, suggested that the degree of magnesium absorption was not only positively correlated to the intraluminal magnesium concentration but also inversely correlated to the intestinal transit time.

Previous studies on infants with familial hypomagnesemia have suggested the existence of a defect in the intestinal absorption of
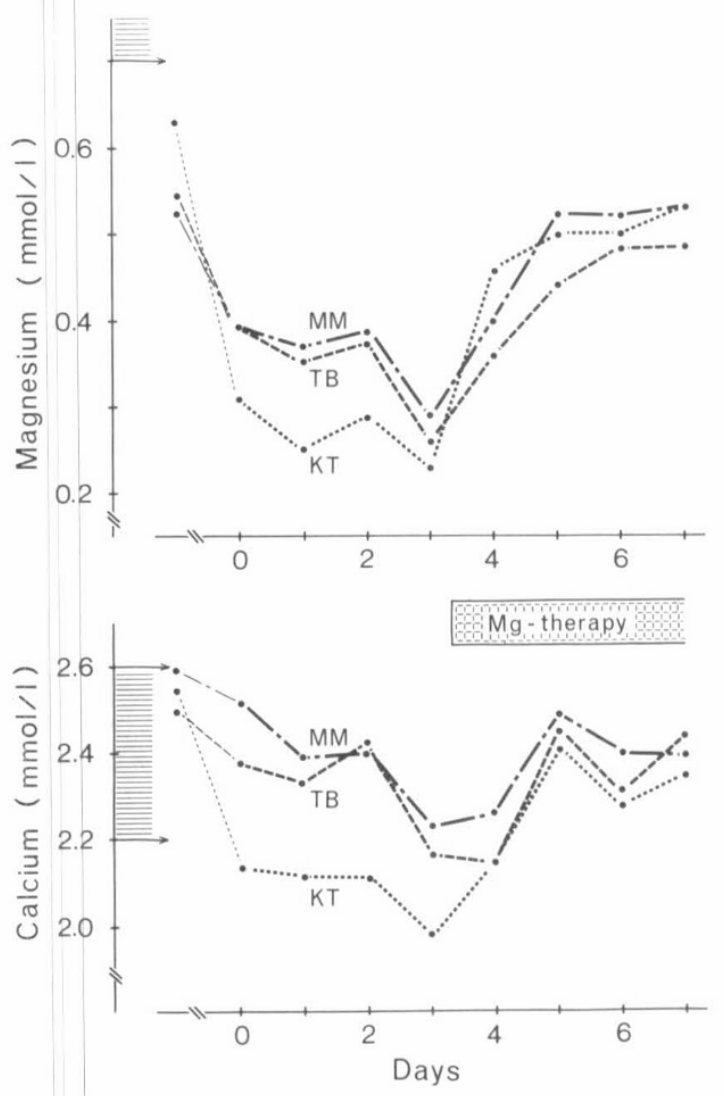

Fig. 6. Concentration of magnesium (upper part) and calcium (lower part) in serum of the three patients while hospitalized. Magnesium supplementation $(0.5 \mathrm{mmole} / \mathrm{kg}$. day $)$ was started on the fourth day as indicated.

magnesium $(23,26,28,32)$. This conclusion is supported by the results reported here. Healthy adults on an ordinary diet (about $10 \mathrm{mmoles} /$ day) excrete in feces 50 to $60 \%$ of the magnesium injected (1). Studies with experimentally induced magnesium deficiency both in animals and man $(9,27)$ have shown an adaptive increase in the magnesium absorption as a deficiency develops. The absorption may in fact approximate $100 \%$ (5) Therefore, an absorption of less than 25\% (average, 13\%) as observed in our three magnesium-deficient children, seems to confirm the presence of an intestinal defect.

A low absorption was also found for calcium (less than $35 \%$, average $18 \%$ ). However, we have no reason to believe that there was also an absorption defect for this cation. Thus, a spontaneous return of serum Ca to normal levels occurred when magnesium alone was given. Moreover, the calcium absorption for $\mathrm{K}$. T. in the neonatal period was found to average about $50 \%$, which had also previously been shown for T. B. (32\%).

Previously, we had found that K. T. absorbed ${ }^{85}$ strontium to a high degree in the neonatal period (see "Subjects"). On this occasion, the three subjects absorbed on an average of $17 \%$ of a single oral load. This is on the same order of magnitude found for calcium. The data, therefore, do not seem to support the findings by Nordio et al. (19) of an absorption defect also for strontium.

Normally, there is a positive correlation between the urinary excretion of calcium and magnesium (expressed, e.g., in $\mu$ moles/ liter glomerular filtrate) and the level of these minerals in plasma (i.e., the ultrafiltrable fraction) (18). This relationship is particularly evident at plasma concentrations below normal when low serum values are followed by low urinary values because of a reduction in the filtered load. Therefore, a low urinary magnesium concentration, as found in our subjects, does not exclude the presence of a defect in the tubular reabsorption mechanism because the plasma concentration was reduced in this period, too. However, when matching the excretion rate with the plasma levels, the values for all three subjects fell below and to the right of an 
experimentally determined correlation curve both for magnesium and for calcium (Figs. 7 and 8). This indicates that the reabsorption of these ions was, in fact, stimulated. The findings seem to exclude the presence of a renal defect of functional importance. Our patients therefore must be different from the one recently described by Nutbeam et al. (20). Their patient was considered to have a combined renal and intestinal magnesium transport defect and showed, in contrast to ours, moderate hypercalcemia.

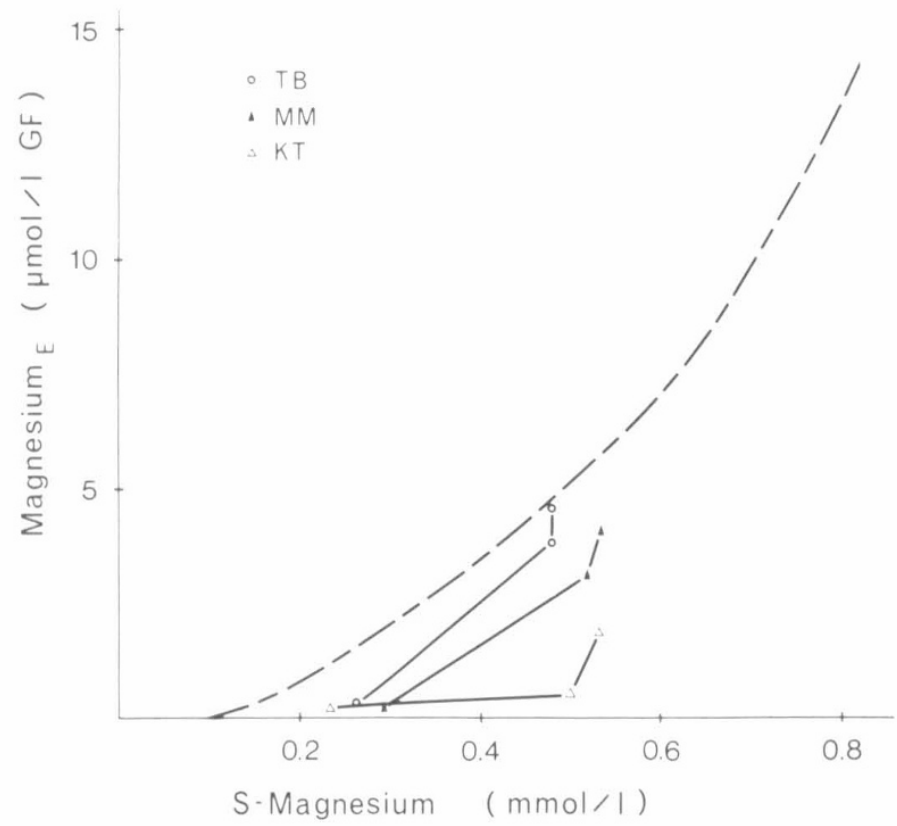

Fig. 7. The relation between serum concentration and urinary excretion of magnesium in the three patients during a period without magnesium treatment [after 3 days in hospital, Fig. 6 (left points)] and with treatment [after 6 and 7 days in hospital, Fig. 6 (right points)]. The broken curve represents a reference curve based on results from 28 normal subjects and 13 subjects after magnesium depletion (remodified from Ref. 19, Fig. $5.19)$.

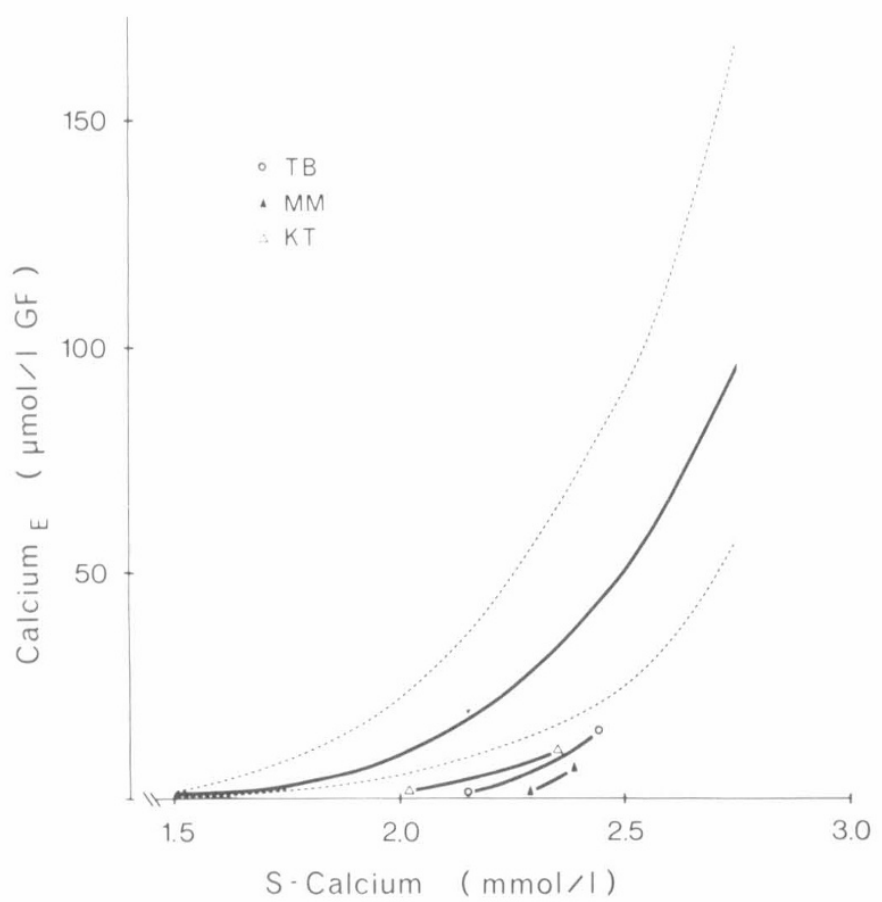

Fig. 8. The relation between serum concentration and urinary excretion of calcium in the three patients under conditions as given in Figure 7. Reference ranges are indicated by the broken curves (redrawn from Ref. 19, Fig. 13.2).
Our three subjects provided an unique possibility for examining the secondary effects of a primary magnesium deficiency. Hypomagnesemia-induced hypocalcemia, resistant to calcium therapy, is the most prominent and regular secondary electrolyte change. All of our subjects showed a consistent but moderate fall in serum calcium as hypomagnesemia developed. Several theories have been proposed to explain the pathophysiologic mechanisms underlying this type of hypocalcemia $(8,29)$. These include: a reduced peripheral response to PTH $(17,19,21,37)$; a reduced synthesis/release of PTH from the parathyroid gland (2, 3, 33); increased serum calcitonin (33); decreased active vitamin D metabolites (e.g., 1,25-diOH-Vit-D) (16,21); and an abnormal distribution of calcium among the various body compartments $(25,32)$.

Most frequently, PTH has been considered to be involved. Several authors have found reduced or blocked peripheral response to PTH $(19,37)$. Others have reported evidence suggesting a reduced synthesis/release of PTH. Thus, Anast et al. (2) and Suh et al. (33) described a low serum PTH in the hypomagnesemic/hypocalcemic period in familial hypomagnesemia and a spontaneous increase in serum PTH on magnesium therapy (2). In contrast, the serum PTH level in our three subjects was within the normal range during the hypomagnesemic and hypocalcemic periods. This suggests an inappropriate response of the parathyroid gland (Fig. 2). Moreover, there was no significant change in serum levels of PTH on magnesium therapy (Fig. 2). In this respect, the literature is extremely controversial. High, normal, and low values have been described in patients with profound hypomagnesemia (29). Both methodologic and pathophysiologic factors may have caused these descrepant observations. The peripheral response to parenteral PTH was not tested, but indirect evidence for an intact response was found in an efficient renal reabsorption of calcium (Fig. 8). On the other hand, a reduced response may be interpreted from finding a high normal tubular absorption of phosphate (TRP) value during the hypomagnesemic period (M. M., 92\%; T. B., 93\%; K.T., 89\%), and a higher urinary excretion during magnesium therapy (T. R. P.: M. M., 86\%; T. B., $88 \%$; K. T., $87 \%$ ). TRP was always within our reference range ( 83 to $95 \%$ ). Consequently, a significant block in renal response to PTH seems unlikely. Normal levels were also found for calcitonin and 25-OH-vitamin D [including the vitamin D binding Gcprotein in serum (14)]. The present data, therefore, failed to provide evidence that any of the hormones PTH, calcitonin, or vitamin $\mathrm{D}$ metabolites are essential in the development of the secondary hypocalcemia.

Hypomagnesemia-induced hypokalemia, resistant to potassium therapy, has also been shown in animal experiments and recently observed in man $(27,36)$. It seems to be less frequent and less marked than the corresponding hypocalcemia, but occurred in our subjects on both occasions when magnesium supplementation was discontinued (Fig. 1). There was simultaneous fall in serum potassium and a slight increase in serum sodium (Fig. 1). Earlier studies have failed to show significant alterations in serum sodium (27). Similarly, an increase in serum phosphate occurred in our patients. On $\mathrm{Mg}$ therapy, the serum phosphate fell as the urinary excretion increased (results not shown) and the TRP decreased. An increasing serum phosphate and a spontaneous fall after magnesium administration have also been noticed in experimental magnesium deficiency, but the reported findings have been inconsistent (27). No difference was found in the serum osmolality either with or without therapy.

Familial hypomagnesemia appears to be an autosomal recessive disorder $(6,28,31)$, but it is most frequently diagnosed in boys. The biochemical substrate for the malabsorption has not as yet been found, but a causal defect or absence of a specific protein (enzyme) is likely. In fact, the detailed mechanism by which magnesium is transported across cell membranes is still unclear (1).

REFERENCES AND NOTES

I. Aikawa, J. K.: Biochemistry and physiology of magnesium. World Rev. Nutr. Diet., 28: 112 (1978)

2. Anast, C. S., Mohs, J. M., Kaplan, S. L., and Burns, T. W.: Evidence for 
parathyroid failure in magnesium deficiency. Science (Wash. D.C.). 177:606 (1972).

3. Anast. C. S., Vinnacker, J. L., Forte, L. R., and Burns, T. W.: Impaired release of parathyroid hormone in magnesium deficiency. J. Clin. Endocrinol. Metab.. 42: 707 (1976).

4. Bardier, A., Barthe, P., Suau, E., Carriére, J.-P., and Ribot, C.: A propos d'une observation d'hypocalcémie magnésio-dépendante chez un nourrisson. Arch. Fr. Pediatr., 26: 879 (1970).

5. Barnes, B. A.. Cope, O., and Harrison, T.: Magnesium concentration in the human being on a low magnesium diet. J. Clin. Invest., 37: 430 (1958).

6. Becker, K.. Lombeck, I., and Bremer, H. J.: Primäre Hypomagnesiæmie. Klinischer Verlauf, diagnostische und therapeutische Untersuchungen bei drei Kindern. Montatsschr. Kinderheilkd., 129:37 (1979).

7. Coenegracht, J. M., and Houben, H. G. J.: Idiopathic hypomagnesemia with hypocalcemia in an adult. Clin. Chim. Acta, 50:349 (1974).

8. Diaz Curiel, M., Castrillo, J. M., Rapado, A., Esbrit, P., and Serrano, M.: The effect of PTE infusion in hypomagnesemic states. Adv. Exp. Med. Biol., 103: 273 (1978).

9. Dunn, J. J., and Walser, M.: Magnesium depletion in normal man. Metabolism. 15: 884 (1966).

10. Friedman. M.. Hatcher. G., and Watson. L.: Primary hypomagnesemia with secondary hypocalcemia in an infant. Lancet, $1: 703$ (1967).

11. Gautvik, K. M., Normann, T., Teig, V., Wille, S. Ø., Brennhovd, I. O., and Christensen. I.: Radioimmunoassay of human calcitonin in serum and tissue from healthy individuals and patients with medullary carcinoma of the thyroid gland. Scand. J. Clin. Lab. Invest., 36: 323 (1976).

12. Gautvik, K. M., Teig, V., Halvorsen, J. F., Arnesen, E., Myhre, L., Heimann. P., and Tollman, R.: Development of sequence specific radioimmunoassay of human parathyroid hormone and its use in the diagnosis of hyperparathyroidism. Scand. J Clin. Lab. Invest., 39: 469 (1979).

13. Haijamäe. H., and MacDowall, J. G.: Distribution of divalent cations at the cellular level during primary hypomagnesemia in infancy. Acta Pædiatr. Scand., 61: 591 (1972).

14. Imawari, M., and Goodman, D. S.: Immunological and immunoassay studies of the binding protein for vitamin D and its metabolites in human serum. J. Clin. Invest. 59: 432 (1977).

15. Lombeck, I., Ritzl, F., Schnippering, H. G., Michael, H., Bremer, H. J., Feinendegen, L. E., and Kosenow. W.: Primary hypomagnesemia. I. Absorption studies. Z. Kinderheilkd.. /18: 249 (1975).

16. Medalle, R., Waterhouse, C., and Hahn, T. J.: Vitamin D resistance in magnesium deficiency. Am. J. Clin. Nutr., 29: 854 (1976).

17. Muldowney, F. P., Mckenna, T. J., Kyle, L. H., Freaney, R., and Swan, M. Parathormon-like effect of magnesium replenishment in steatorrhea. N. Engl. J. Med. 282:61 (1970)

18. Nordin, E. E. C. (Ed.): Calcium, phosphate and magnesium metabolism. Clinical physiology and diagnostic procedures. pp. 186-216 (Churchill Livingstone. New York, 1977).

19. Nordio, E., Donath, A., Macagno, F., and Gatti, R.: Chronic hypomagnesemia with magnesium-dependent hypocalcemia. I. A new syndrome with intestinal magnesium malabsorption. II. A study of relationship between magnesium. calcium and strontium. Acta Pædiatr. Scand., 60:441, 449 (1971).

20. Nutbeam, H. M.. Sinclair, L., and Oberholzer, U. Q.: Magnesium transport defect with hypocalcemia. J. Roy. Soc. Med.. 72: 932 (1979).

21. Passer, J.: Incomplete distal renal tubular acidosis in hypomagnesemia-dependent hypocalcemia. Arch. Intern. Med., 136: 462 (1976).
22. Paunier, L.. Radde. I. C., Kooh, S. W.. and Fraser. D.: Primary hypomagnesemia with secondary hypocalcemia. J. Pediatr., 67: 945 (1965)

23. Paunier, L. Radde, I. C. Kooh. S. W. Conen, P. E. and Fraser. D.: Primary hypomagnesemia with secondary hypocalcemia in an infant. Pediatrics. 4i: 385 (1968).

24. Pouillaude, J-M. Frederich, A., François, B. Racle, P. Pernod, J., and François, R.: Hypomagnesemie congenitale primitive et chronique avec hypocalcemie magnesio-dependante. Arch. Fr. Pediatr., 28: 1021 (1971).

25. Reddy, C. R., Coburn, J. W., Hartenbower, D. L., Friedier, R. M., Brickman, A S.. Massry, S. G., and Jowsey, J.: Studies on mechanism of hypocalcemia of magnesium depletion. J. Clin. Invest.. 52: 3000 (1973).

26 Salet. J. Polonovski, C. De Gouyon. F. Pean, Q., Melekian, B. and Fournet, J. P.: Tetanic hypocalemique recidivante par hypomagnesemie congenitale. Arch. Fr. Pediatr.. 7: 749 (1966)

27. Shils, M.: Experimental human magnesium depletion. Medicine (Baltimore), 48 . 61 (1969)

28. Skyberg. D., Strømme, J. H.. Nesbakken. R.. and Harnæs, K.: Neonatal hypomagnesemia with selective malabsorption of magnesium. Scand. J. Clin. Lab. Invest.., 21: 355 (1968)

29. Slatopolski. E., Rosenbaum, R., Mennes, P., and Klahr. S.: The hypocalcemia of magnesium depletion. Adv. Exp. Med. Biol.. 103: 263 (1978).

30. Smales, O. R. C.: Primary infantile hypomagnesæmia. Proc. Roy. Soc. Med., 67: 759 (1974).

31. Strømme, J. H.: Interrelationship between calcium and magnesium in vivo studied in infants with a specific defect in the intestinal absorption of magnesium (familial hypomagnesemia). pp. 47-63 (Collett Nutrition Symposia, Bye and Snorre, Oslo. Norge 1970).

32. Strømme, J. H., Nesbakken, R., Normann. T., Skjørten, F., Skyberg. D., and Johannessen. B.: Familial hypomagnesemia. Biochemical, histological and hereditary aspects studied in two brothers. Acta Pædiatr. Scand.. 58: 433 (1969)

33. Suh. S. M. Tashjian. Jr. A. H., Matsuo. N., Parkinson. D. K., Fraser. D. Pathogenesis of hypocalcemia in primary hypomagnesemia: normal end-organ responsiveness to parathyroid hormone, impaired parathyroid gland function. J. Clin. Invest.. 52: 153 (1973)

34. Vainsel, M. Vandevelde, G.. Smulders, J., Voster. M., Hubain. P.. and Loeb. H. Tetany due to hypomagnesemia with secondary hypocalcemia. Arch. Dis. Child., 45: 254 (1970).

35. Vik. T.. Try. K., and Strømme, J. H.: The vitamin D status of man at $70^{\circ}$ north. Scand. J. Clin. Lab. Invest., 40: 227 (1980)

36. Whang. R., and Aikawa, J. K.: Magnesium dificiency and refractoriness to potassium repletion. J. Chronic Dis., 30: 65 (1977)

37. Woodard, J. C., Webester, P. D., and Carr, A. A.: Primary hypomagnesmia with secondary hypocalcemia, diarrhea and insensitivity to parathyroid hormone. Dig. Dis. Sci., 17: 612 (1972).

38. The parents had given their full and informed consent to the examinations, and the mothers stayed with the patients during the whole hospital period.

39. PTH and calcitonin determinations were kindly performed by Dr. K. M. Gautvik, the Research Institute of Surgery. Rikshospitalet, Oslo, Norway

40. The authors want to thank Sylvia Nome Kvam for excellent technical assistance and Dr. John Boulton for valuable help in preparing the manuscript.

41. Requests for reprints should be addressed to: Professor Johan H. Strømme, M.D.. Department of Clinical Chemistry Ulleval Hospital, Oslo I. Norway.

42. Received for publication May 7, 1980

43. Accepted for publication February 2, 1981 